\title{
INTERFACE METÁFORA E METONÍMIA INSCRITAS NAS CONCEPÇÕES DE VIOLÊNCIA ENTRE ESTUDANTES BRASILEIROS E FRANCESES
}

\author{
Meire Virginia Cabral Gondim ${ }^{1}$ \\ Ana Cristina Pelosi ${ }^{2}$
}

\begin{abstract}
RESUMO
A metáfora e a metonímia são recursos eminentemente humanos, presentes na linguagem da vida cotidiana, ambas consideradas estruturas de pensamento. No entanto, muitas vezes, essas manifestações misturam-se a ponto de não conseguirmos estabelecer de fato as fronteiras entre elas. Por isso objetivamos analisar a construção de metáforas e de metonímias e suas inter-relações nas concepções de violência de jovens com idade média de 11-13 anos, estudantes de duas escolas situadas nas cidades de Fortaleza, Ceará e Libourne, França. O trabalho foi realizado com base na pesquisa qualitativa, tendo como eixo um estudo comparativo que possibilitou-nos analisar a complexidade da construção de sentidos da categoria VIOLÊNCIA em termos sociocognitivos e culturais. O corpus analítico é constituído de trechos de entrevistas realizadas com 24 estudantes, divididos em 06 grupos de 04 integrantes (12 brasileiros, 12 franceses). A leitura e a análise dos dados basearam-se nos aportes teóricos da Linguística Cognitiva, em especial, a Teoria Cognitiva da Metáfora e da Metonímia - TCMM. A inter-relação metáfora/metonímia mostrou-se evidente quando os dois grupos discorreram sobre os sentimentos decorrentes de ações violentas, como a dor e a tristeza e quando usaram partes do corpo para comunicar esses sentimentos. Os dois grupos, ao conceptualizarem a violência, utilizaram-se de processos metafóricos e metonímicos o que nos permite sugerir uma universalidade parcial dos esquemas cognitivos de base corpórea para comunicar e expressar sentimentos.
\end{abstract}

Palavras-Chave: Violência. Metáfora. Metonímia. 


\section{INTRODUÇÃO}

A metáfora e a metonímia são recursos eminentemente humanos presentes na linguagem da vida cotidiana, sendo ambas consideradas estruturas de pensamento. No entanto, muitas vezes manifestações desses dois recursos misturam-se a ponto de não conseguirmos estabelecer, de fato, as fronteiras entre eles. Por essa razão, objetivamos neste estudo, analisar a construção de metáforas e de metonímias e suas inter-relações emergentes nas concepções de violência de jovens, com idade média de 11-13 anos, estudantes de duas escolas situadas nas cidades de Fortaleza, Ceará e Libourne, França.

O presente trabalho é parte de uma tese de Doutorado, que propôs um estudo comparativo em que analisamos a heterogeneidade, a singularidade e a complexidade do processo de significação da categoria VIOLÊNCIA em termos sociocognitivos e culturais. O corpus analítico é constituído de trechos de entrevistas realizadas com 24 estudantes, divididos em 06 grupos de 04 integrantes (12 brasileiros e 12 franceses). Realizamos entrevistas coletivas com os grupos e utilizamos a Técnica de palavras-chave em que os alunos escreveram em um pedaço de papel três palavras que julgavam estar relacionadas com a violência e cada participante explicou o porquê da escolha. As entrevistas foram gravadas em áudio e vídeo e depois transcritas.

A leitura e a análise dos dados basearam-se nos aportes teóricos da Linguística Cognitiva - LC, em especial para esse artigo, a Teoria Cognitiva da Metáfora e da Metonímia - TCMM. A inter-relação metáfora e metonímia (metaftonímia) evidenciou-se quando os dois grupos discorreram sobre os sentimentos decorrentes de ações violentas, sobretudo a dor, a tristeza e o medo.

Organizamos nosso texto da seguinte maneira: primeiro, apresentamos os aportes teóricos da metáfora, da metonímia e da metaftonímia, depois apresentamos e analisamos os dados empíricos contidos nos trechos representativos das entrevistas e, em seguida, tecemos as considerações finais. 


\section{METÁFORAS, METONÍMIAS E SUAS INTER-RELAÇÕES- METAFTONÍMIAS}

A metáfora é um mecanismo eminentemente humano e o seu uso é parte integrante da linguagem da vida cotidiana. As formas de pensar; de compreender; de dizer; de convencer e explicitar o que se pensa, muitas vezes não são possíveis na ausência de metáforas, porque sem usá-las perde-se o sentido daquilo que, de fato, se deseja dizer. Por essas razões, ela é um dos mecanismos simbólicos mais estudados em Encontros Nacionais e Internacionais em LC - investigada em diferentes perspectivas da linguagem em uso e em suas variadas manifestações: linguísticas, gestuais, pictóricas (GIBBS, 2006; GRADY, 1997; JOHNSON,1987; KÖVECSES, 2000, 2005, 2010; LAKOFF, 1987; LAKOFF; JOHNSON, 1980; ORTONY, 1993).

Lakoff e Johnson (1980) afirmam que o nosso sistema conceptual, em grande parte, é naturalmente metafórico, uma vez que é reflexo direto da maneira como falamos e agimos no mundo, porque as expressões na ordem da metáfora formam sistemas complexos que são baseados em metáforas conceituais, estando na base da linguagem e do pensamento.

Para Silva (2003, p. 2) "a metáfora é um importante mecanismo cognitivo pelo qual domínios da experiência mais abstractos e intangíveis podem ser conceptualizados em termos do que é mais concreto e imediato". Dessa maneira, o arcabouço teórico da Metáfora Conceptual baseia-se nos pressupostos da Semântica Cognitiva e da Visão Experiencialista. Por exemplo, em Seguiremos caminhos diferentes porque não nos amamos mais, temos a metáfora conceitual AMOR É UMA VIAGEM, em que o domínio conceitual mais "concreto", viagem, é evocado para estruturar um domínio conceitual mais "abstrato" e subjetivo, o domínio conceitual alvo "amor". Dessa forma, "amor" é compreendido em termos de viagem.

No que diz respeito à metonímia, na vertente da LC, ela é concebida como uma projeção conceitual em que um domínio experiencial (FONTE) é parcialmente 
entendido em termos de outro domínio experiencial (ALVO), ambos subjacentes a um domínio experiencial comum (BARCELONA, 2003).

Para Lakoff (1987), o modelo metonímico tem as seguintes características: há um conceito alvo A a ser compreendido para algum objetivo em algum contexto; existe uma estrutura conceptual que contém $A$ e um outro conceito $B$; $B$ é qualquer parte de A ou com uma associação bem próxima de A na estrutura conceptual; uma escolha de B determinará A dentro da estrutura conceptual; comparada a A, B é mais fácil de entender, mais fácil de lembrar, mais fácil de identificar ou mais imediatamente útil para determinado propósito em determinado contexto; o modelo metonímico é um modelo de como $\mathrm{A}$ e $\mathrm{B}$ estão relacionados em uma estrutura conceptual, sendo o relacionamento especificado por uma função de B para A. Um exemplo clássico é $O$ sanduíche de presunto pediu a conta, em que temos um mesmo domínio conceitual ligado à lanchonete em que o PEDIDO está pelo CLIENTE, isto é, a PARTE PELO TODO.

Kövecses e Radden (1999) afirmam que a metonímia assenta-se em três suposições: i- é um fenômeno conceptual; ii- é um processo cognitivo; iii- opera dentro de um Modelo Cognitivo Idealizado. Na primeira suposição, a metonímia é considerada um fenômeno conceptual porque se funda em nossas experiências; está sujeita a princípios conceituais gerais e sistemáticos que estruturam nossos pensamentos e ações.

Lakoff (1987) demonstrou que um membro de uma categoria pode abarcar a categoria inteira porque responde aos efeitos prototípicos. O membro mais saliente da categoria representa não apenas a utilização de um termo pelo outro, mas reflete uma escolha operacionalizada em nível conceptual. Em vista disso, a metonímia é considerada uma das mais ricas fontes de efeitos prototípicos, pois, em sua essência, ela está estruturada a partir do princípio de que um membro de uma categoria, uma subcategoria ou um submodelo, é tomado como representativo da categoria ou do modelo como todo. Outro aspecto de relevância é evidenciar que quando o elemento passa a representar toda uma categoria, ele é tomado como "ponto de referência cognitivo", estabelecendo efeitos de tipicidade.

Como podemos observar, as metonímias configuram-se em um processo cognitivo que explora o fato de haver uma ligação pragmática entre as entidades, sendo mais um exemplo de construção linguística, mas não apenas sustentada pelo aparato cognitivo socioculturalmente situado. Apesar de discutirmos separadamente 
os conceitos de metáfora e de metonímia, elas não são excludentes, podendo ocorrer de forma simultânea e estar em constante processo de interação. Por exemplo, os participantes de nossa pesquisa, ao discorrerem sobre as suas concepções de violência, usaram expressões linguísticas que nos autorizavam a empreender análises tanto sob um ponto de vista metafórico quanto metonímico. Essas inter-relações foram estudadas por Goossens (2003) que designou 0 fenômeno de metaftonímias.

Silva (2003) incorpora esse termo, quando discorre sobre as tendências teóricas de alguns autores (BARCELONA 2003; 2009; RADDEN 2003; RADDEN, KÖVECSES,1999) vinculados a LC, embora sob diferentes enfoques. O conjunto de estudos sobre a interação metáfora e metonímia - metaftonímia, cujo pilar assentase na natureza metafórica de grande parte do sistema conceitual humano e o alcance cognitivo da metonímia, está sob a denominação de Teorias Cognitivas da Métafora e da Metonímia- TCMM.

Goossens (2003) sustenta a ideia de que as metaftonímias, geralmente, são baseadas em partes do corpo. $O$ autor, em síntese, apresenta dois grupos de ocorrências: i- metaftonímia integrada e a ii- metaftonímia cumulativa. A primeira refere-se a metonímia dentro de uma metáfora e a metáfora dentro de uma metonímia. Nesses casos, podem-se analisar a combinação de metáfora e de metonímia em uma mesma expressão. Por exemplo, na expressão "cortar a língua", temos um domínio fonte cuja projeção metafórica evoca um domínio mais abstrato e subjetivo. $O$ sentido pode ser arrepender-se daquilo que se pronunciou; não repetir 0 que se disse; autopunição simbólica. Tal projeção torna-se possível pela integração da metonímia: LíNGUA ESTÁ PELA FACULDADE DE FALAR, ou seja, a PARTE PELO TODO.

Já a metaftonímia cumulativa é quando temos a construção de uma metáfora a partir de uma metonímia. Os domínios fonte e alvo podem estar ligados de forma natural e simultânea em uma única cena complexa - situação que conta sempre com a presença de metonímias servidas como base para a interpretação metafórica. Nesse sentido, a leitura metonímica é necessária para formação da metáfora; essa formação apresenta uma ligação com a sua origem metonímica. O exemplo citado é "boca fechada", podendo significar não falar os segredos dos outros, ser discreto, em que os lábios unidos estão pela capacidade de a pessoa guardar segredo. 
Radden (2003, p. 93) comenta em seu artigo How metonymic are metaphors? que:

\begin{abstract}
Metonímia baseada em metáfora supera, pelo menos, parte do problema criado por limitar um estudo de uma ou outra categoria particular. Em vez de sempre querer separar os dois, podemos muito mais pensar em um continuum metonímia metáfora com evidentes casos fuzzy no meio. Metonímia e metáfora podem ser vistas como categorias prototípicas nos extremos deste continuum.
\end{abstract}

Segundo o autor, os dois fenômenos sociocognitivos e culturais do pensamento e da linguagem estão inter-relacionados e distingue quatro tipos de metonímias baseadas em metáforas com diferentes motivações entre domínios conceptuais, aqueles: i- de base experiencial comum: realizados a partir de metáforas primárias (Grady,1997) correlacionadas ou complementares aos elementos dos dois domínios: MAIS ESTÁ EM CIMA; IMPORTANTE É GRANDE; ii- por implicatura: acontece, por exemplo, na metáfora CONHECER É VER; VER É COMPREENDER, engendrando ações que ocorrem simultaneamente ou sucessivamente, ligadas aos domínios perceptivos; iii- baseados em estrutura de categorias: em que as relações metonímicas entre uma categoria e os seus elementos mais salientes podem ser de origem metafórica, no exemplo, "Ele feriu-me com suas palavras", a ofensa verbal é entendida em termos de dano físico corporal, então OFENSA VERBAL É DANO FíSICO e finalmente, iv- baseados em modelos culturais, cujas concepções e crenças são comunicadas, produzidas a partir de domínios conceituais metafóricos e metonímicos, por exemplo, COMUNICAR É MANDAR; COMUNICAR É TRANSFERIR, segundo a metáfora do CANAL de Reddy (1979), como na expressão: " O professor não conseguiu passar o conteúdo".

Para finalizar, citaremos Cuenca e Hilferty (1999). Eles argumentam acerca da importância de reconhecer que a metáfora e a metonímia não podem ser operações cognitivas mutuamente incompatíveis, porque algumas expressões linguísticas se apropriam dos dois processos. As situações discursivas socioculturalmente motivadas e o desejo de eficácia comunicativa com vistas à construção de sentidos, colaboram para a ocorrência de metaftonímias. Por exemplo, "Carlos saiu com o rabo entre as pernas", a interpretação global da expressão metafórica, sair com o rabo entre as pernas envolve uma base metonímica: RABO ENTRE AS PERNAS ESTÁ PARA CACHORRO que se aparta de um rival mais forte com medo e foge. 
Essa interpretação é evocada pela cena da parte física do cachorro em retirada que orienta o significado.

Para esclarecer, no domínio conceitual de cães, a posição do rabo do cachorro colado entre as pernas implica em submissão. Dessa forma, há uma dedução metonímica do tipo PARTE PELO TODO. A partir dessa metonímia, projetamos a imagem dessa cena para o domínio das pessoas, metaforizando O CAMINHAR DE UMA PESSOA HUMILHADA em termos da RETIRADA DE UM CACHORRO DERROTADO. Com esse exemplo, os autores advogam que, longe de serem domínios excludentes, a metáfora e a metonímia funcionam de forma conjunta e complementar visando à produção de sentidos.

Nesta seção, tivemos por objetivos esclarecer os conceitos de metáforas e de metonímias, bem como compreender as suas inter-relações, as metaftonímias de modo a investigar como essa relação está intrínseca ao discurso dos participantes quando discorrem acerca de suas concepções de violência. Passemos a seguir às análises e discussão dos dados.

\section{ANÁLISE E DISCUSSÃO DOS DADOS}

Para o estudo das inter-relações metáfora e metonímia, extraímos os trechos das entrevistas coletivas mediadas por palavras-chave dos participantes de língua portuguesa e francesa. Em cada fragmento, colocamos em negrito o trecho significativo da análise. Selecionamos as palavras-chave morte, insultos, xingamentos e palavra.

A primeira palavra-chave dita por Marcos foi morte e para justificar a escolha, ele narra durante a entrevista o caso do caminhoneiro. Em suma, o participante contou que um caminhoneiro chegou à oficina para consertar o seu caminhão, desceram próximos a ele, dois homens em uma moto, e o "garupeiro" deu dois tiros na cabeça do dono do caminhão que chegou ao hospital sem vida.

Os participantes disseram que o motivo da morte poderia ter sido vingança, prestação de contas e especularam o porquê de uma pessoa gastar uma bala, que não é barata, para se vingar, discutindo no intuito de compreender o que se passa na mente de um assassino. Eis o trecho destacado: 
96 MM1BG: eu num entendo porque o povo num tá cobrando dinheiro e num tá devendo... por que o cara vai gastar uma bala que é:: caro.. dez reais mais ou menos um cartucho de balas deve ser uns quarenta reais...gastar bala pra (vingar) uma dívida de mais ou menos cinco reais...pra quê...gastar bala que é mais caro?

97 PESQ1: o que é que vocês acham?

98 TFBG1: porque... tem o prazer de matar

99 MMBG1: pois é mas...

100SFBG1: melhor pagar mais caro e matar do que...éh::...matar [que] deixar...

101 TFBG1: na cabeça deles né?

A expressão linguística "na cabeça deles" pode ser analisada tanto do ponto de vista metafórico como metonímico. Primeiro, ela licencia a metáfora conceptual MENTE COMO UM LUGAR, um lugar de difícil acesso, onde estão COISAS, isto é, as ideias. Podemos considerar também que metaforicamente a MENTE É UM RECIPIENTE e as IDEIAS SÃO OBJETOS. Assim, matar alguém para vingar o não pagamento de uma dívida é melhor do que manter o devedor vivo é a ideia que se encontra na forma de pensar do assassino e, para dar conta disso, o participante utiliza metáforas baseadas em uma metonímia o TODO PELA PARTE, em que o termo cabeça (TODO), ponto de referência, é usado para se referir à mente (PARTE), zona ativa. A leitura da Figura 1, explicita a relação entre os domínios:

\section{Figura 1 - Metáfora vs Metonímia}

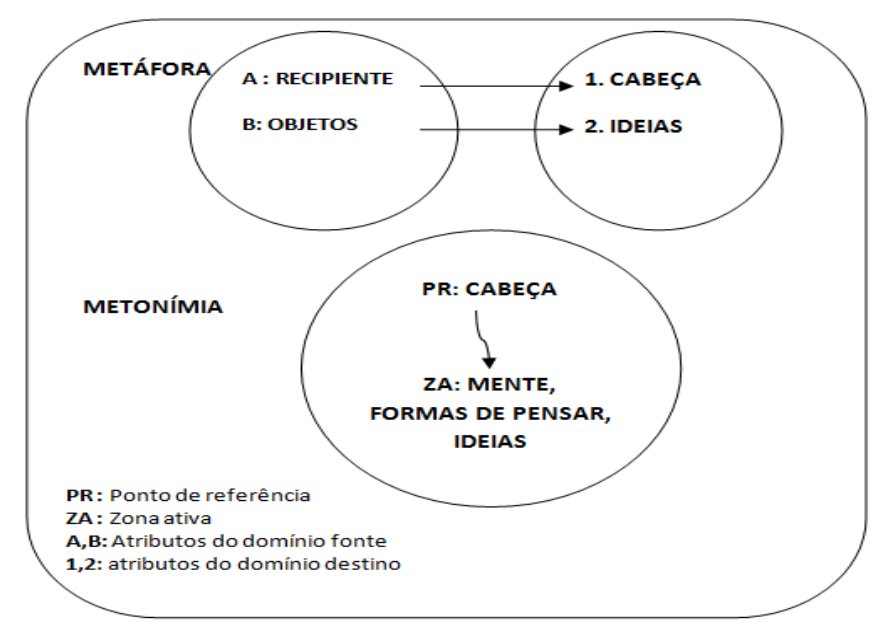

Fonte: Baseado em Cuenca, Hilfert (1999)

A cabeça é tomada pela faculdade de pensar, o elemento compartilhado (i.e. cabeça como parte do corpo e cabeça como local onde a mente se situa) funciona de forma metonímica no domínio alvo, interpretado literalmente no domínio fonte na 
medida em que na cabeça encontra-se a mente, que em termos metafóricos é um lugar ou um recipiente em que há ideias.

Essa relação metáfora e metonímia pode ser exemplificada a partir de expressões linguísticas que envolvem não apenas a cabeça, mas outros órgãos do corpo como a boca, quando Telma menciona a palavra-chave xingamentos ou insultos em contexto familiar:

\footnotetext{
325 TF1BG: eu vou falar tia é porque assim óh porque tem assim óh que minha irmã ela chama os filhos dela de vagabundo de boiola de viado minha mãe diz assim "menina num fala isso não porque se ele for um dia tu vai reclamar se eles forem ser...tu bate na boca"

326 SF1BG: a boca tem poder

327 TF1BG: tu bate na boca pra tu dizer isso viu? por que se eu te pegar dizendo isso e teus filho for tu nunca vai se perdoar
}

A interpretação metafórica global das expressões "tu bate na boca" e "a boca tem poder" são construídas sob uma base metonímica, neste caso a metáfora e a metonímia funcionam conjuntamente e de forma complementar para colaborar com a construção de significados. Na primeira expressão "tu bate na boca", a ação de BATER NA BOCA é entendida metaforicamente em termos de não agredir mais verbalmente os filhos, pois agredir teria consequências ruins para os próprios filhos e para a mãe, caso o que ela dissesse viesse a acontecer.

De uma forma figurada BATER NA BOCA É DESTRUIR O QUE SE DISSE, é tentar impedir que o dito aconteça. Em uma perspectiva metonímica, temos um dos órgãos da fala, a BOCA, pela função de FALAR. Desse modo BATER NA BOCA É NÃO AGREDIR MAIS VERBALMENTE O FILHO; BATER NA BOCA É AUTOPUNIÇÃO; BATER NA BOCA É CALAR-SE.

$\mathrm{Na}$ ocorrência a "boca tem poder", o conteúdo das palavras que saem da BOCA tem o poder de fazer as coisas acontecerem. Então, para Sara, participante em foco, a boca é personalizada como um agente capaz de fazer acontecer o que a mãe diz como ser "vagabundo", "viado", "boiola" porque a boca, metaforicamente tem poder para isso. Por outro lado, podemos identificar uma metonímia, o órgão BOCA pela função FALAR, a função estaria relacionada à emissão de palavras de conteúdo insultuoso, isto é, de palavras não apropriadas para uma mãe falar aos filhos.

Para exemplificar ainda a perspectiva teórica da realização da metáfora com fontes metonímicas que envolvem partes do corpo, extraímos do grupo de 
estudantes franceses, trechos em que o coração foi evidenciado como lugar de emoções inerente à metáfora CORAÇÃO É O CENTRO DAS EMOÇÕES, quando explica a escolha da palavra-chave insulto. $O$ ambiente da ação de violência não foi especificado porque o participante francês apresenta a situação de forma genérica:

\footnotetext{
65 PESQ1: Pourquoi l'insulte c'est une forme de violence pour toi ? (PESQ1: Por que o insulto é uma forma de violência para você?)

66 JMFG5: Ben parce que ça peut toucher beaucoup plus fort, profondément la personne, au cœur... (JMFG5: Bom, porque isso pode tocar muito mais forte, profundamente a pessoa, no coração....)

67 PESQ1: Touche au cœur... ça ça fait mal? (PESQ1: Tocar o coração....isso isso faz mal?)

68 JMFG5: Euh non pas forcément euh... on a toujours plus mal au cœur qu'au corps. (JMFG5: Euh não forçosamente euh....há sempre mais mal ao coração que ao corpo)
}

As agressões verbais, segundo Jerome, são um tipo de violência que causa um mal até mesmo mais forte que uma violência física, porque toca o coração. $A$ metáfora implicada é VIOLÊNCIA VERBAL TOCA O CORAÇÃO; VIOLÊNCIA VERBAL FAZ MAL AO CORAÇÃO. A título de exemplo de semelhança de pensamento dos participantes franceses e brasileiros, vale a pena inserir o trecho pronunciado por Ronald que cita também o coração, como RECIPIENTE prototípico das emoções:

\footnotetext{
RMBI: A violência pra mim... é uma forma de agredir pessoas (...) a [violência] física deixa dores mas passam e as verbais não ...elas ficam no coração da pessoa

PESQ2: ah então quer dizer que a violência física ela deixa ela deixa?

RMBI: Ahham?

PESQ2: deixa o quê?

RMBI: A agressão física deixa marcas mas com o tempo elas saem mas a agressão como é que eu posso dizer...verbal não ...dói mais machuca o coração
}

Ronald, do mesmo modo que o estudante francês compreende o coração como um RECIPIENTE que contém o sofrimento causado pela agressão verbal. Há recorrência da metáfora ESTADOS EMOCIONAIS SÃO ENTIDADES DENTRO DE UMA PESSOA, "elas ficam dentro do coração", não mais para se referir ao órgão cabeça (como no exemplo do desejo de vingança do assassino do caminhoneiro), mas dessa vez, ao coração. Sabemos que uma agressão verbal, em geral, não faria mal ao órgão do coração, mas à pessoa completa em toda sua plenitude emocional, moral e psicológica. Em vista disso, o processo metonímico é constituído da PARTE 
(órgão do ser humano) PELO TODO (a pessoa humana), conforme destacamos na figura a seguir:

\section{Figura 2 - Metáfora vs Metonímia}

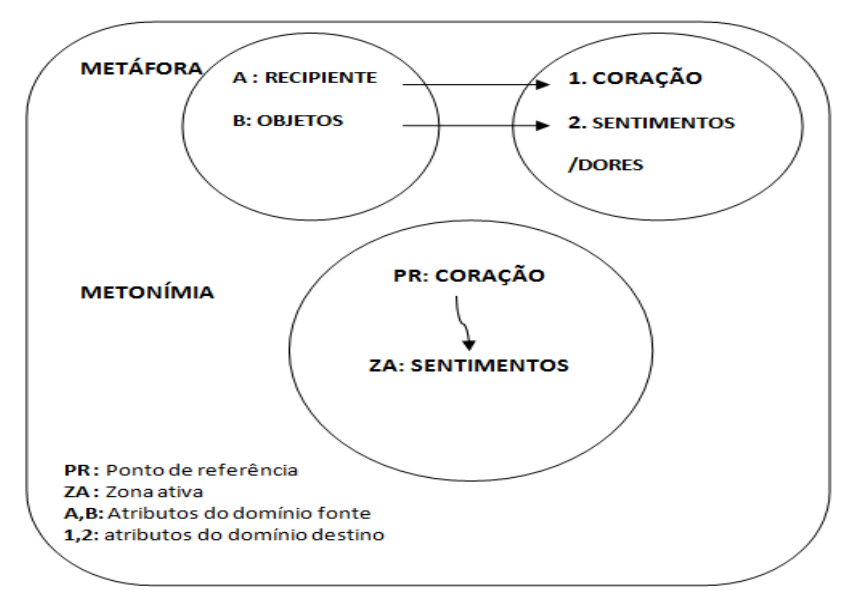

Fonte: Baseado em Cuenca; Hilfert (1999)

Ainda em relação ao coração, ao discutirmos por que determinadas pessoas tornam-se violentas, matam por causa de dez centavos, cinquenta centavos e por ciúmes, os participantes centralizam-se no órgão coração como um RECIPIENTE que abriga sentimentos como a maldade, responsável pelos atos de violência, conforme explicitado nos trechos em que foram questionados os motivos de certas pessoas cometerem atos violentos e outras não:

\section{GFBG2: porque tem umas que têm maldade no coração (...) \\ 77 JMBG2: tem o coração de pedra}

Mais uma vez, o coração é visto de forma metonímica a PARTE PELO TODO e de forma metafórica CORAÇÃO CENTRO DAS EMOÇÕES. Ele é retratado como um lugar em que se aloja a maldade, vista metaforicamente como um objeto manipulável: VIOLÊNCIA É TER MALDADE NO CORAÇÃO. Ainda para entender os motivos de uma pessoa cometer violência e outras não, os estudantes mencionam que VIOLÊNCIA É TER O CORAÇÃO DE PEDRA. Ter o "coração de pedra" é quando a pessoa pratica a violência sem demonstrar arrependimento, age com frieza. A pedra é impenetrável, dura, logo a pessoa não ficaria sensibilizada, ou não teria sentimentos de empatia ao cometer atos de violência, seria uma pessoa dura, conforme a leitura da figura sugere: 


\section{Figura 3 - Metáfora vs Metonímia}

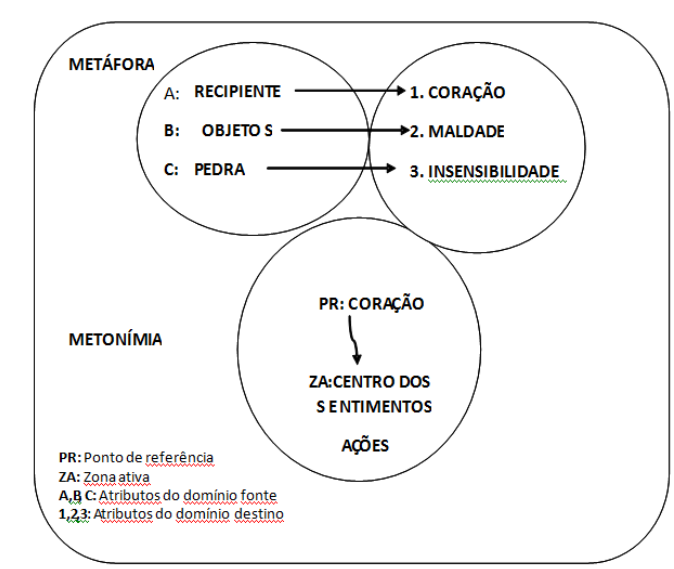

Fonte: Baseado em Cuenca; Hilfert (1999)

Citaremos outro exemplo, para investigar a manifestação da metáfora e da metonímia, no que diz respeito à violência verbal e as suas consequências, conceptualizada em termos corpóreos. Entendemos que as estruturas conceptuais são comunicadas de formas semelhantes, independentes da cultura e da língua, logo extraímos mais uma fala de uma jovem francesa, no momento em que ela explica o termo escolhido (palavra-chave), palavra para discorrer sobre violência:

\footnotetext{
117 MFFG5: Et la parole. (MFFG5: E a palavra)

118 PESQ1: La parole... pourquoi? (PESQ1: A palavra.....por quê?)

119 MFFG5: Ben... souvent ....ben la parole ça peut vraiment, même si, enfin je sais pas mais je connais des filles, des copines qui des fois... disent des paroles, mais pour rire, mais qui peuvent vraiment blesser des gens au fond du cœur, et ça... c'est... vraiment la parole c'est... (MFFG5: Bem...sempre...bem a palavra isso pode verdadeiramente ferir, mesmo se, enfim eu não sei mas eu conheço garotas, colegas que às vezes...dizem palavras, mas para rir, mas que pode verdadeiramente ferir as pessoas no fundo do coração, e isso...é...verdadeiramente a palavra é...)
}

Interessante notar que Myriam escolheu a palavra-chave palavra com 0 objetivo de associá-la à categoria VIOLÊNCIA, em especial, a subcategoria VIOLÊNCIA VERBAL e, posteriormente, em sua justificativa, citou um exemplo de colegas que usam a palavra como instrumento de violência - falam coisas sobre as outras amigas com o objetivo de rir ou debochar, ação que tem como consequência ferir e magoar a vítima.

Do mesmo modo que no exemplo anterior, a palavra é usada como instrumento de violência verbal que pode atingir o coração da pessoa, isto é, os sentimentos, a autoestima, a dignidade. A PALAVRA ESTÁ PELO CONTEÚDO DESAGRADÁVEL, 
uma vez que não são as palavras em si que agem violentamente, mas o significado das palavras; o que elas representam e os efeitos que elas podem causar, quando são dirigidas a alguém. Ferir em sentido restrito, refere-se a usar algo, ou ter um objeto cortante, perfurante, capaz de ferir alguém ou alguma coisa, entretanto o termo é usado em sentido metafórico, embora pouco perceptível devido ao seu uso no cotidiano: FERIR É CAUSAR MAL-ESTAR OU DANO PSICOLÓGICO; A PALAVRA FERE O CORAÇÃO, A PALAVRA É UM INSTRUMENTO DE VIOLÊNCIA.

Em vista dos exemplos escolhidos, observamos que a maneira de conceptualizar a violência verbal é semelhante nos dois grupos de jovens, franceses e brasileiros, em relação à linguagem figurada comunicada de forma metonímica e metafórica. A partir dessas análises, podemos concluir que a saliência perceptual de violência, expressas pelos estudantes nos dois países foi prototípica, no que tange ao uso metafórico e metonímico, ou seja, em relação à violência verbal, a palavra foi utilizada pelos dois grupos como instrumento prototípico que machuca e fere o órgão coração, órgão representado metaforicamente como centro das emoções.

Ao focalizarmos a palavra como instrumento de violência, na perspectiva de Radden (2003), a relação é metonímica, porque a FORMA de linguagem, a palavra, é representada pelo seu CONTEÚDO: insultos, xingamentos e agressões verbais. Para o autor, "forma e conteúdo são noções complementares, as quais são assumidas como inseparáveis".

Desse modo, compreender a palavra como um RECIPIENTE, leva-nos a combinação da metonímia RECIPIENTE PELO CONTEÚDO e da metáfora estruturada a partir do esquema CONTEÚDO DENTRO DE UM RECIPIENTE em que o significado estaria dentro da palavra. Para as concepções veiculadas, temos os seguintes acarretamentos: A PALAVRA É UM INSTRUMENTO DE VIOLÊNCIA; A PALAVRA CAUSA DANOS, A PALAVRA É RECIPIENTE DE INSULTOS.

\section{CONSIDERAÇÕES FINAIS}

Em vista do que se discutiu acerca das concepções de violência de estudantes brasileiros e franceses, pudemos constatar a interação em diversos fragmentos, da metáfora e da metonímia - metaftonímia. Na produção de metáforas, os domínios fonte e alvo são ligados de maneira natural e simultânea em uma cena complexa 
que permitiu a formação de metonímias - temos a cena em que a mãe "xinga" os filhos e, ao descrever e analisar essa situação, a participante explica suas concepções com uso de expressões fundadas em metaftonímias, por exemplo, quando diz que "a boca tem poder" (ocorrência 326 SF1BG).

As análises evidenciaram que a metaftonímia acontece na evocação de partes do corpo em que a identificação da metonímia serve de suporte para a ocorrência da metáfora como nos casos: da cabeça, do coração e da boca. Neste sentido, não raro os estudantes utilizam expressões linguísticas que podem ser analisadas na perspectiva da metáfora e da metonímia, em que partes do corpo são constitutivas. Nos exemplos focalizados, a metáfora se estabelece a partir de um processo metonímico PARTE PELO TODO, uma vez que na cabeça se localiza a mente, na boca a faculdade de falar e o coração é significado como centro das emoções, operações sociocognitivas que visam a garantir a flexibilidade e a eficácia comunicativa.

Dessa forma, podemos inferir que quando discorremos sobre sentimentos, formas de pensar e de agir no mundo, podemos recorrer a processos metafóricos e metonímicos, isso independente da cultura e da língua, fato que nos permite sugerir uma universalidade parcial dos esquemas cognitivos de base corpórea, com fontes metonímicas interligadas aos processos de construção metafóricos, ou seja, o fenômeno metaftonímico.

\section{NOTAS}

1 Doutora em Linguística pela Universidade Federal do Ceará- UFC com Estágio - CAPES na Universidade Michel de Montaigne Bordeaux3. Pós-doutoranda do Programa de Pós-Graduação em Linguística/CAPES. Email: meirevirginia@hotmail.com.

2 Doutora em Linguística e Psicologia pela Universidade de Leeds, Inglaterra. Professora Associada da Universidade Federal do Ceará, Programa de Pós-Graduação em Linguística. Email: anapelosi2009@gmail.com. 


\title{
INTERFACE AND METAPHOR METONYMY PRESENT IN THE CONCEPTUALIZATIONS OF VIOLENCE BY BRAZILIAN AND FRENCH STUDENTS
}

\begin{abstract}
Metaphor and metonymy are eminently human resources present in the language of everyday life, both considered structures of thought. However, these manifestations are often mixed to the point that the boundaries between them cannot be established. This paper therefore, aims at analysing the construction of metaphors and metonymies and their interrelationships in the conceptions of violence by young people within the age range of 11 to 13 years, students of two schools located in Fortaleza, Ceara, Brazil and Libourne, France. The qualitative research carried out on the data made possible a comparative analysis of the complexity of sense construction of the category VIOLENCE in sociocognitive and cultural terms. The analysed corpus consists of excerpts from interviews conducted with 24 students, divided into 06 groups, each composed of 04 members (12 Brazilian students and 12 French students). The reading and analysis of the data were based on theoretical contributions of cognitive linguistics, in particular, the Cognitive Theory of Metaphor and Metonymy - CTMM. The interrelation/metaphor metonymy proved to be evident when the two groups spoke about feelings resulting from violent actions, like pain and sorrow and when they used parts of the body to communicate these feelings. The conceptualizations of violence by the two groups involved metaphorical and metonymic processes which allow us to suggest a partial universality of bodily cognitive schemas in the communication and expression of feelings.
\end{abstract}

Keywords: Violence. Metaphor. Metonymy.

\section{REFERÊNCIAS}

BARCELONA, A. Metaphor and metonymy at the crossroads: a cognitive perspective. Berlin: Mouton de Gruyter, 2003.

2009.

. O poder da metonímia. Cadernos de tradução, Porto Alegre n. 25, p. 7-24, 
CUENCA, M. J; HILFERT, J. Introducción a la lingüística cognitiva. Barcelona, 1999.

GIBBS, R. W. Jr. Embodiment and cognitive science. New York: Cambridge University Press, 2006.

GOOSSENS, L. Metaphtonymy: the interaction of metaphor and metonymy in expressions for linguistic action. In: DIRVEN, R.; PÖRING, R. (Eds.). Metaphor and metonymy in comparison and contrast. Berlin: New York: Mouton de Gruyter, [1990] 2003.

GRADY, J. E. Foundations of meaning: primary metaphors and primary scenes. Tese de doutorado, inédita. University of California. Berkeley, 1997.

JOHNSON, M. The body in the mind: the bodily basis of meaning, imagination and reason. Chicago, USA: Cambridge University Press, 1987.

KÖVECSES, Z. Metaphor and emotion: language, culture and body in human feeling. Cambridge: Cambridge University Press, 2000.

. Metaphor and culture. New York: Cambridge University Press, 2005.

. Metaphor: a practical introduction. Oxford: University Press, 2010.

LAKOFF, G. Women, fire and dangerous things: what categories reveal about the mind. Chicago: University of Chicago Press, 1987.

LAKOFF, G.; JOHNSON, M. Metaphors we live by. London: The University of Chicago Press, 1980.

ORTONY, Andrew. (Org.). Metaphor and thought. 2. ed. Cambridge : Cambridge University Press. 1993.

RADDEN, G. How metonymic are metaphors? In: René Dirven, Ralf Pöring (Eds.). Metaphor and metonymy in comparison and contrast. Berlin: New York: Mouton de Gruyter, 2003.

RADDEN, G.; KÖVECSES, Z. Towards a theory of metonymy. In: PANTHER, K-U; RADDEN, G. (Eds.). Metonymy in language and thought. Amsterdam: John Benjamins Publ., 1999.

REDDY, $M$. The conduit metaphor : a case of frame conflict in our language about language. In ORTONY, A. (Org.). Metaphor and thought. Cambridge: Cambridge University Press, 1979.

SILVA, A. S. O poder cognitivo da metáfora e da metonímia. Revista portuguesa de humanidades, Braga, Faculdade de Filosofia da Universidade Católica Portuguesa, v. 7, n. 1-2, p. 13-75, 2003. 